\title{
REVISIÓN
}

\section{Características de los casos graves de influenza en la provincia de Santa Fe durante el año 2016}

Recibido: 19-07-2017 Aceptado: 22-10-2017

\section{Gabriela Nilva', Natalia Mordini', Andrea Uboldi², Carolina Cudós², Mirta Villani², Pedro Morana², Marisa Prause², Marta Calderón².}

\section{Resumen}

Introducción: La infección por influenza puede conllevar a graves complicaciones, y poner en riesgo la vida. El objetivo de este trabajo fue describir las características de los casos graves confirmados de influenza en la Provincia de Santa Fe durante el año 2016.

Materiales y métodos: Descripción epidemiológica a partir de los datos de las fichas individuales ETI (enfermedades tipo influenza) de los casos de síndrome gripal atendidos en los servicios de salud de la provincia. Resultados: De un total de 211 casos graves confirmados, 63 fallecieron. El subtipo viral detectado con mayor frecuencia fue influenza A H1N1 (87,67\%). La mayor letalidad se produjo entre los mayores de 65 años (57,58\%). La chance de morir fue 2,7 veces mayor en los casos en los que la administración del antiviral se demoró más de 48 horas de iniciados los síntomas (IC: 1,01-7,40; $\mathrm{P}<0,05$ ). Los factores de riesgo con mayor prevalencia fueron: EPOC $(28,48 \%)$, edad menor de 5 años y pacientes obesidad (23,84\%). La chance de morir fue 2,4 mayor en aquellos que presentaban al menos un factor de riesgo (OR: 2,397; 1,119-5,132; $p<0,05)$. De 22 vacunados, 4 fallecieron $(18,18 \%)$, todos con algún factor de riesgo asociado, mientras que de 148 no-vacunados, 50 fallecieron (33,78\%), 40 con al menos algún factor de riesgo asociado.

Conclusión: La información epidemiológica recabada es importante para organizar y priorizar los recursos de salud de manera eficiente, principalmente en aquellos grupos en los que la gravedad de la enfermedad puede llevar a la muerte. Palabras clave: influenza, caso grave confirmado.

"Instituto Nacional de Enfermedades Respiratorias "Dr. Emilio Coni". Pcia. de Santa Fe. Argentina.

${ }^{2}$ Ministerio de Salud de la Provincia de Santa Fe. Argentina.

Dirección para correspondencia:

Dra. Gabriela Nilva.

Necochea 4637 "1". 3000 Santa Fe. Provincia de Santa Fe. Argentina. +549342 4087908. E mail: gabriela.nilva@gmail.com

Ninguno de los autores declara presentar conflicto de intereses con relación a esta publicación. 


\section{Introducción}

La influenza es una enfermedad viral que se caracteriza por causar afección respiratoria y ser altamente transmisible. La mayoría de los afectados se recupera en una o dos semanas sin necesidad de recibir tratamiento médico, sin embargo, en personas con factores de riesgo asociados, puede conllevar a graves complicaciones y poner en riesgo la vida $(1,2)$.

En Argentina es una enfermedad de notificación obligatoria, de manera que los distintos establecimientos de salud, tanto públicos, privados como de la seguridad social, deben recolectar la información sobre los pacientes atendidos, consolidarla de manera diaria o semanal (según corresponda) y notificarla al Sistema Nacional de Vigilancia de la Salud (SNVS) (3).

Además, en la provincia de Santa Fe, para todos los casos graves de síndrome gripal que requieren de internación hospitalaria, el efector en cuestión completa en cada caso una ficha individual específica ETI (enfermedad tipo influenza), que se remite junto con la muestra de hisopado o aspirado nasofaríngeo al laboratorio de referencia donde se realiza la confirmación del evento mediante PCR. El laboratorio de referencia para la zona Centro-Norte de la provincia es el Laboratorio Central de la Provincia de Santa Fe (ciudad de Santa Fe), y para la zona Sur, el Centro de Especialidades Médicas Ambulatorias (ciudad de Rosario) (4).

El objetivo de este este trabajo fue describir y caracterizar los casos de influenza hospitalizados confirmados en la provincia de Santa Fe durante el año 2016. Consideramos que la descripción epidemiológica y análisis de las características de los casos graves de influenza, incluidos aquellos con desenlace fatal, puede resultar de utilidad para plantear posibles acciones preventivas con miras a reducir el impacto de esta enfermedad en la provincia, así como orientar la priorización de recursos cuando esta sea necesaria a aquellos grupos en los que las consecuencias de la enfermedad puedan ser más graves.

\section{Metodología}

Se realizó una descripción epidemiológica de los casos graves de influenza en la provincia de Santa Fe durante el año 2016 a partir de los datos provenientes de las bases de datos de casos estudiados por laboratorio y de los casos confirmados proporcionadas por la Dirección Provincial de Epidemio- logía de la Provincia de Santa Fe. Dichas bases fueron confeccionadas a partir de las fichas individuales específicas ETI de todos los casos de síndrome gripal grave atendidos en los servicios de salud de la Provincia de Santa Fe que remitieron muestras a los laboratorios oficiales para confirmar o descartar la enfermedad mediante análisis de PCR.

La población objetivo de estudio estuvo constituida por los casos graves confirmados de influenza para la provincia de Santa Fe durante 2016. Definimos operativamente como caso grave confirmado a todo aquel caso sospechoso de influenza que requirió hospitalización y contó con un diagnóstico positivo a virus influenza mediante técnica PCR realizada por un laboratorio oficial.

Para la caracterización de dichos casos, se analizó la distribución y frecuencia de los mismos según el tipo viral detectado y las variables sexo, edad, lugar y tiempo, mediante cálculo de porcentajes y tasas. Con un fin comparativo, se describieron las mismas características para los casos graves de influenza notificados en el año 2015. Las tasas de incidencia por zonas de la provincia de Santa Fe y las tasas de mortalidad se calcularon a partir de las proyecciones poblacionales obtenidas del Instituto Nacional de Estadística y Censo (INDEC 2010).

Los días de demora en la consulta médica se calcularon por diferencia en días entre la fecha de inicio de síntomas gripales y la fecha en la que el paciente consultó al médico por dichos síntomas. Los días de demora en la administración del antiviral se calcularon por diferencia en días entre la fecha de inicio de síntomas y la fecha de administración de oseltamivir. El análisis de la asociación entre los días de demora y el evento de la muerte se realizó mediante el cálculo del Odds Ratio (OR) con un intervalo de confianza (IC) del $95 \%$ y su significancia estadística.

El análisis de la asociación entre el número de casos de influenza fallecidos y distintos factores de riesgo, se realizó mediante el cálculo del OR con un IC del $95 \%$ y su significancia estadística.

Los datos de cobertura de vacunación para la población en estudio se obtuvieron de las fichas individuales ETI de cada paciente y del Sistema de Información de los Centros de Atención Primaria (SICAP). 


\section{Resultados}

\section{Número de casos y porcentaje de positividad}

En 2016, de un total de 1.020 casos internados graves con sospecha clínica de influenza, $211(20,69 \%)$ resultaron positivos, mientras que en 809 casos $(79,31 \%$ de los internados) no se detectó el virus. En 2015, de un total de 1.017 internados con sospecha clínica de influenza, solo 73 casos $(7,18 \%)$ resultaron positivos.

\section{Distribución geográfica de los casos y las defunciones}

En 2016, la mayor cantidad de casos positivos se registró en la Zona Sur de la provincia (Nodo Rosario y Nodo Venado Tuerto), concentrando ésta $134(63,51 \%)$ de los mismos. La Zona Centro-Norte (Nodo Santa Fe, Nodo Rafaela y Nodo Reconquista) aportó $77(36,49 \%)$ de los casos confirmados. Tanto la tasa de incidencia por 100.000 habitantes de casos graves de influenza como la tasa de mortalidad por 100.000 habitantes específica por zona fueron superiores para la Zona Sur respecto a la Centro-Norte: 6,74 frente a 5,37 y 2,46 frente a 0,98 respectivamente.

Un total de 37 localidades registraron casos graves de influenza, 15 de la Zona Centro-Norte y 22 de la Zona Sur. Las localidades de la Zona Centro-Norte que mayor cantidad de casos graves de influenza concentraron fueron Santa Fe (45 casos), Santo Tomé ( 7 casos) y Rafaela (6 casos), mientras que en la Zona Sur fueron Rosario (96 casos), Cañada de Gómez (4 casos) y Venado Tuerto (4 casos).

Del total de 211 casos graves notificados en 2016 en la provincia de Santa $\mathrm{Fe}, 63$ resultaron en muerte, lo que significó una letalidad del $29,86 \%$. De dichas defunciones, 14 ocurrieron en la Zona CentroNorte (letalidad: 18,18\%) mientras que 49 en la Zona Sur (letalidad: 36,57\%). En 2015 se notificó un total de 14 defunciones $(19,18 \%)$ entre el total de casos graves, y al igual que en 2016, la Zona Sur presentó la mayor cantidad de las muertes (8 fallecidos) respecto a la zona centro norte ( 6 fallecidos), aunque la letalidad fue superior en la Zona Centro-Norte, $22,22 \%$ frente a $17,39 \%$ en la Zona Sur.

\section{Frecuencia y distribución de casos de influenza según subtipo viral actuante}

En 207 (98,10\% del total) de los casos graves de influenza confirmados en 2016 en la provincia de Santa Fe se detectó el virus tipo A, correspondien- do en un $89,37 \%$ al subtipo $\mathrm{H} 1 \mathrm{~N} 1$, en un $1,45 \%$ al subtipo H3N2, y un $9,18 \%$ no contando con subtipificación viral. En el 1,90\% restante de los casos totales el virus de influenza detectado correspondió al tipo B.

En 2015 , en 57 (78,08\% del total) de los casos graves confirmados se detectó el virus tipo $A$, correspondiendo un $22,81 \%$ al subtipo $\mathrm{H} 1 \mathrm{~N} 1$, un $64,91 \%$ al subtipo H3N2, y un $12,28 \%$ no contó con subtipificación viral. En el 21,92\% restante de los casos totales el virus de influenza detectado correspondió al tipo $B$.

En 62 de los casos de influenza que resultaron en muerte $(98,42 \%$ del total de fallecidos) se detectó el virus tipo A, correspondiendo el $91,94 \%$ de éstos al subtipo H1N1. Para el 8,06\% restante de los casos totales no se contó con información respecto a su subtipificación. Sólo en 1 caso $(1,59 \%)$ se detectó virus tipo $B$.

Por otro lado, en el año 2015, en $10(71,43 \%)$ de los casos de influenza que terminaron en muerte se detectó el virus influenza tipo A, que en $6(60 \%)$ de los casos correspondió al subtipo AH3N2 y en $4(40 \%)$ al subtipo A H1N1. El virus tipo B se detectó en $4(28,57 \%)$ de los casos fallecidos durante ese año.

El subtipo de virus influenza $A \mathrm{H} 1 \mathrm{~N} 1$ y el tipo $\mathrm{B}$ tuvieron un $30,80 \%$ y $25,00 \%$ de letalidad en los casos graves de influenza, respectivamente, tanto en 2015 como en 2016. La letalidad del subtipo A H3N2 en los casos graves fue de un $16,20 \%$ en 2015 , mientras que en 2016 no tuvo muertes asociadas.

\section{Frecuencia y distribución de casos de influenza por semana epidemiológica (SE)}

En el año 2016, el primer caso de influenza en la provincia de Santa Fe fue detectado por una Unidad Centinela (UC) en la SE15. Ya en la SE17 se registró el primer caso grave que requirió internación. La mayor cantidad de casos graves se registró en las SE20 y SE21, las cuales concentraron un 16,11\% (34 casos) de los mismos cada una. El 98,10\% de los casos graves se produjo entre la SE17 y SE30 (fines de abril a fines de julio), sin embargo, la aparición esporádica de nuevos casos graves continuó durante el resto del año, registrándose el último en la SE52 (fines de diciembre). En el año 2015, por otro lado, los casos graves confirmados se produjeron entre la SE22 y SE46, registrándose la mayor cantidad en la SE31 (20,55\%, 15 casos). 
La primera defunción de un caso con diagnóstico de influenza del año 2016 en la provincia se produjo en la SE18, y la última en la SE30. $42(66,67 \%)$ de las muertes ocurrieron entre las SE22 y SE25, siendo la SE23 la que concentró la mayor cantidad, con $12(19,05 \%)$ muertes. En 2015, la primera defunción tuvo lugar en la SE25, y la última en la SE48. Cuatro $(28,57 \%)$ muertes se produjeron durante la SE31. En ninguna otra semana epidemiológica hubo más de 2 muertes totales, situación que se produjo en la SE27, concentrando el $14,29 \%$ del total (Figura 1).

\section{Frecuencia y distribución de casos de influenza por grupos de edad}

En 2016, la categoría con mayor cantidad de casos fue la de 45 a 54 años, seguida por la de 55 a 64 años. Ambos grupos presentaron la mayor tasa de incidencia, después de los menores de 2 años. Por otro lado, los menores de 2 y los mayores de 65 años, considerados grupos de riesgo para el desarrollo de formas graves de influenza, concentraron el 13,74\% y $15,64 \%$ de los casos, respectivamente (29 y 33 casos, respectivamente). No se contó con información sobre la edad en $5(2,37 \%)$ casos.

En 2015, los menores de 2 años concentraron el $41,1 \%$ de los casos graves y los mayores de 65 años el $9,59 \%$ de los mismos, con 30 y 7 casos graves respectivamente. El mayor número de casos y la tasa de incidencia más alta se observó en los menores de 1 año (Tabla 1).

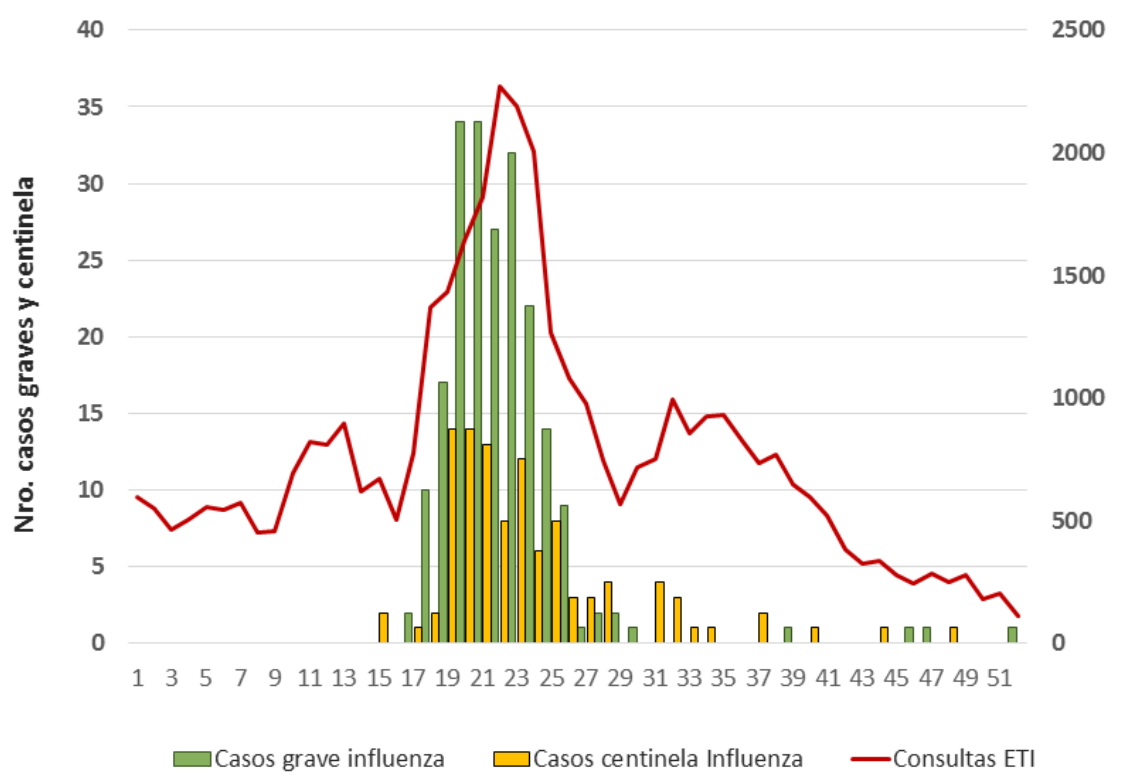

Figura 1. Distribución por SE de las consultas por ETI, casos centinela y casos graves confirmados de influenza. Provincia de Santa Fe. Año 2016.
Tabla 1. Cantidad de casos graves de influenza y tasa de incidencia por 100.00 habitantes por grupo de edad

\begin{tabular}{ccccc}
$\begin{array}{c}\text { Grupo etario } \\
\text { (en años) }\end{array}$ & \multicolumn{2}{c}{$\mathbf{2 0 1 5}$} & \multicolumn{2}{c}{2016} \\
\hline $\mathbf{N}^{\mathbf{0}}$ de casos & $\begin{array}{c}\text { Tasa de } \\
\text { incidencia }\end{array}$ & $\mathbf{N}^{\mathbf{0}}$ de casos & $\begin{array}{c}\text { Tasa de } \\
\text { incidencia }\end{array}$ \\
\hline 1 & 23 & 42,68 & 18 & 33,43 \\
\hline 2 a 4 & 7 & 12,99 & 11 & 20,42 \\
\hline 5 a 14 & 5 & 3,11 & 5 & 3,10 \\
\hline 15 a 24 & 2 & 0,59 & 10 & 1,97 \\
\hline 25 a 34 & 4 & 0,37 & 7 & 1,31 \\
\hline 35 a 44 & 12 & 0,75 & 22 & 4,10 \\
\hline 45 a 54 & 5 & 2,61 & 22 & 4,65 \\
\hline 55 a 64 & 5 & 1,39 & 40 & 11,02 \\
\hline$>65$ & 7 & 1,59 & 38 & 11,94 \\
\hline S/I & 0 & 1,69 & 33 & 7,82 \\
\hline
\end{tabular}

S/l: sin información

En 2016 las defunciones se concentraron en los grupos de edades mayores, principalmente en el grupo de mayores de 65 años $(30,16 \%, 19$ defunciones), seguido por el grupo de 55 a 64 años $(27 \%, 17$ defunciones). No se registraron muertes en menores de 2 años, pero sí en un caso de 3 años. En 2015 el mayor número de defunciones se registró en el grupo de 45 a 54 años $(42,86 \%, 6$ casos $)$, seguido del de mayores de 65 (28,57\%, 4 casos). A diferencia de 2016, no se presentó ninguna muerte en menores de 5 años.

La tasa de mortalidad y el porcentaje de letalidad en los casos graves de influenza ocurridos en los años 2015 y 2016 , según grupo de edad, se muestran en la Tabla 2.

\section{Frecuencia y distribución de casos de influenza por sexo}

Durante el año 2016, los varones E concentraron la mayor cantidad casos graves de influenza: hubo 121 casos $(57,35 \%)$ frente a 90 ca$\operatorname{sos}(42,65 \%)$ correspondientes a mujeres, siendo la razón hombre-mujer de 1,34. Durante el año 2015 hubo 39 casos en varones $(53,42 \%)$ y 34 casos en mujeres (46,58\%), siendo la razón hombre-mujer de 1,15.

Durante el año 2016, el 61,90\% de las muertes se produjo en varones (39 casos) y el 38,10\% (24 casos) en mujeres. La letalidad para hombres fue del $32,23 \%$ y para mujeres del 26,66\%. En 2015, el 71,43\% 


\begin{tabular}{|ccccc|}
\hline $\begin{array}{c}\text { Tabla 2: Letalidad y mortalidad cada } \\
\text { casos graves de influenza por grupo de edad }\end{array}$ \\
$\begin{array}{c}\text { Grupo etario } \\
\text { (en años) }\end{array}$ & $\begin{array}{c}\text { \% de } \\
\text { letalidad }\end{array}$ & $\begin{array}{c}\text { Tasa de } \\
\text { mortalidad }\end{array}$ & $\begin{array}{c}\text { 2016 de } \\
\text { letalidad }\end{array}$ & $\begin{array}{c}\text { Tasa de } \\
\text { mortalidad }\end{array}$ \\
\hline$<1$ & 0,00 & 0,00 & 0,00 & 0,00 \\
\hline 1 & 0,00 & 0,00 & 0,00 & 0,00 \\
\hline 2 a 4 & 0,00 & 0,00 & 20,00 & 0,62 \\
\hline 5 a 14 & 0,00 & 0,00 & 0,00 & 0,00 \\
\hline 15 a 24 & 50,00 & 0,19 & 0,00 & 0,00 \\
\hline 25 a 34 & 0,00 & 0,00 & 45,45 & 1,86 \\
\hline 35 a 44 & 25,00 & 0,65 & 22,73 & 1,06 \\
\hline 45 a 54 & 60,00 & 0,83 & 27,50 & 3,03 \\
\hline 55 a 64 & 60,00 & 0,95 & 44,74 & 5,34 \\
\hline$>65$ & 57,14 & 0,97 & 57,58 & 4,50 \\
\hline
\end{tabular}

(10 casos) de las muertes se produjo en varones (letalidad del $25,54 \%$ ), y el $28,57 \%$ ( 4 casos) se produjo en mujeres (letalidad de 11,76\%).

\section{Días de demora en la consulta médica y en la administración del antiviral}

Los datos respecto a los días transcurridos entre la aparición de los síntomas y la consulta al médico estuvieron disponibles para 142 casos graves $(67,30 \%$ del total). Esta variable presentó una amplitud entre 0 y 20 días. La categoría con mayor porcentaje de casos fue la de consulta el mismo día de inicio de los síntomas ( 0 días de demora), con el 23,94\% de los casos. En el $59,15 \%$ de los casos se registró una consulta dentro de los 2 días posteriores al inicio de los síntomas.

Los casos que terminaron en muerte presentaron una distribución similar respecto a aquellos que no presentaron desenlace fatal.

No se encontró asociación estadísticamente significativa entre los días de demora en la consulta médica y la muerte.

Los datos respecto a los días de demora en la administración del antiviral estuvieron disponibles en 78 casos graves $(36,97 \%)$. Esta variable presentó una amplitud entre 0 y 11 días. El promedio, para todos los casos, fue de 4 días; 3 días para los no fallecidos, y 5 días para los fallecidos. La administración del antiviral se produjo durante las primeras 48 horas en el $47,73 \%$ de los casos que no terminaron en muerte, y sólo en el $25 \%$ de aquellos que sí lo hicieron. La chance de morir fue 2,7 veces mayor en los casos en los que la administración del antiviral se demoró más de 48 horas de ini- ciados los síntomas gripales en comparación con los aquellos en los que se administró dentro de las 48 horas (IC: 1,01-7,40; $\mathrm{P}<0,05$ ).

\section{Factores de riesgo asociados}

Los factores de riesgo asociados al desarrollo de complicaciones o formas graves de influenza se detallan a continuación $(2,5)$ :

Edad menor a 5 años.

Edad mayor a 65 años.

Enfermedades respiratorias: enfermedad respiratoria crónica (hernia diafragmática, enfermedad pulmonar obstructiva crónica (EPOC), enfisema congénito, displasia broncopulmonar, traqueostomía crónica, bronquiectasias, fibrosis quística, etc.). Asma moderado y grave.

Enfermedades cardiacas: insuficiencia cardiaca, enfermedad coronaria, reemplazo valvular, valvulopatía. Cardiopatías congénitas.

Inmunodeficiencias congénitas o adquiridas (no hematooncológica): infección por VIH. Utilización de medicación inmunosupresora o corticoides a altas dosis (mayor a $2 \mathrm{mg} / \mathrm{kg} / \mathrm{día}$ de metilprednisona o más de $20 \mathrm{mg} /$ día o su equivalente por más de 14 días). Inmunodeficiencia congénita. Asplenia funcional o anatómica. Desnutrición grave.

Condición oncohematológica y trasplante: tumor de órgano sólido en tratamiento. Enfermedad oncohematológica, hasta seis meses posteriores a la remisión completa. Trasplante de órganos sólidos o tejido hematopoyético.

$\leftrightarrow$ Otros: obesidad mórbida (índice de masa corporal mayor a 40). Diabetes. Insuficiencia renal crónica con diálisis o expectativa de ingresar a diálisis en los siguientes seis meses. Retraso madurativo grave en menores de 18 años de vida. Síndromes genéticos, enfermedades neuromusculares con compromiso respiratorio y malformaciones congénitas graves. Tratamiento crónico con ácido acetilsalicílico en menores de 18 años. Embarazadas (en cualquier trimestre) y puérperas hasta las 2 semanas posparto.

De un total de 211 casos graves confirmados de influenza, 3 no contaron con información respecto a la ausencia o presencia de algún factor de riesgo. Del total de casos con información, $151(72,60 \%)$ registraron al menos alguno de los siguientes factores de riesgo: puerperio, embarazo, asma, EPOC, diabetes, obesidad, enfermedades cardíacas, inmunodepresión, enfermedades renales, síndromes genéticos, enfermedades neuromusculares, malformacio- 
nes congénitas, condición oncohematológica, edad menor a 5 años, y edad mayor a 65 años. En cambio, 57 casos $(27,40 \%)$ no tuvieron ninguno de dichos factores de riesgo. La distribución porcentual de los factores de riesgo observados entre el total de casos graves de influenza con factores de riesgo asociados $(N=151)$ se muestra en la Figura 2.

De las 63 defunciones notificadas, 61 tuvieron datos sobre factores de riesgo asociados. De ellas, $51(83,61 \%)$ tuvo al menos alguno de los factores de riesgo mencionados, mientras que $10(16,39 \%)$ de los fallecidos no tuvo ninguno de dichos factores.

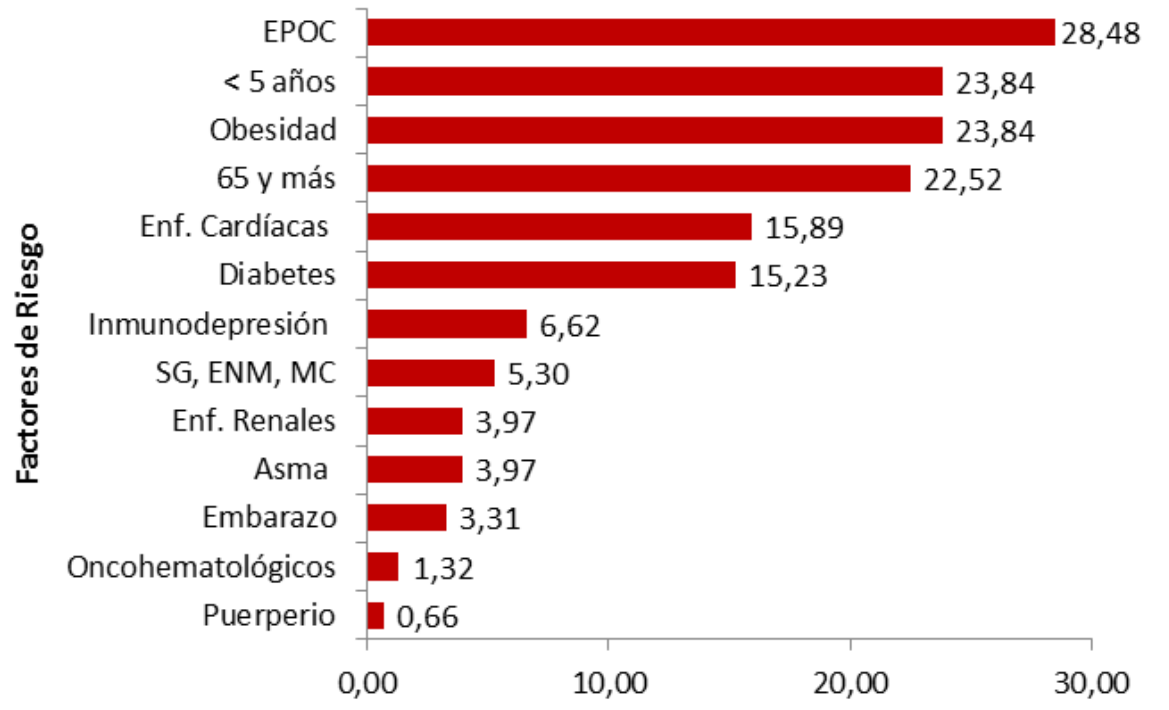

Porcentaje de casos ( $\mathrm{N}=144)$

Figura 2: Factores de riesgo prevalentes en casos graves de influenza de la Provincia Santa Fe, en el año 2016. Enf.: enfermedades. SG: síndromes genéticos. ENM: enfermedades neuromusculares. MC: malformaciones congénitas

A su vez, la chance de morir fue 2,4 veces mayor en aquellos pacientes que tuvieron al menos alguno de los factores de riesgo mencionados respecto a los pacientes que no tuvieron ningún factor de riesgo, y dicha asociación fue estadísticamente significativa (OR: 2,$397 ; 1,119-5,132 ; p<0,05$ ).

El análisis de los factores de riesgo por separado se muestra en la Tabla 3. Para los restantes factores de riesgo prevalentes, la asociación no fue estadísticamente significativa.

Por otro lado, de los 57 casos graves de influenza que no reportaron ninguno de los factores de riesgo mencionados, 10 resultaron en muerte. De estos fallecidos, 2 tenían otras comorbilidades (psitacosis y hepatopatía crónica), 6 eran tabaquistas y/o etilis-

\begin{tabular}{|cccc}
\hline \multicolumn{4}{|c|}{ Tabla 3: Asociación entre factores de riesgo y defunción } \\
de casos graves de influenza
\end{tabular}

*Odds Ratio. ${ }^{\dagger}$ Intervalo de confianza.

tas, 1 era personal de salud y 1 no tenía comorbilidad ni habito nocivo aparente asociado. Ninguno de ellos contaba con aplicación de la vacuna antigripal. De los 47 sobrevivientes $\sin$ factores de riesgo, 40 no contaban con vacunación antigripal.

\section{Vacunación antigripal}

De los 211 pacientes internados con diagnóstico grave de influenza, $170(80,57 \%)$ contaron con información respecto a la cobertura de vacunación, según los datos registrados en el SICAP $(19,43 \%$ sin información). De un total de 22 vacunados $(12,94 \%)$ entre los pacientes con información sobre la cobertura, 4 faIlecieron $(18,18 \%)$, todos con factores de riesgo asociados; mientras que de un total de 148 no-vacunados, 50 fallecieron $(33,78 \%), 40$ de ellos tenían al menos algún factor de riesgo asociado.

La población objetivo de vacunación comprende el personal de salud, embarazadas en cualquier trimestre de la gestación, puérperas hasta el egreso de la maternidad, máximo 10 días (si no recibieron la vacuna durante el embarazo), niños de seis a veinticuatro meses de edad, personas entre dos y 64 años con factores de riesgo y mayores de 65 años (3). Del total de pacientes con información, 148 formaban parte de la población objetivo de vacunación, de los cuales $130(87,84 \%)$ no se habían vacunado contra influenza y 18 sí se habían vacunado $(12,16 \%)$.

No se encontró asociación estadísticamente significativa entre la no-vacunación antigripal y el evento de la muerte, aunque el OR tuvo una intensidad de 2,29 (OR: 2,$295 ; 0,737-7,148 ; p=0,142$ ). 


\section{Discusión}

\section{Caracterización de casos graves y defunciones por influenza}

Las temporadas de influenza varían año a año conforme a una cantidad de factores que incluyen: las características de los virus en circulación, la época del año en que se desarrollan los casos, la efectividad de la vacuna para proteger contra la infección, y la cantidad de personas que se vacunaron (6).

La cantidad total de casos graves registrados en la provincia de Santa Fe en el año 2016 fue casi 3 veces mayor que en 2015. En 2016 tanto la tasa de incidencia de casos graves de influenza como la tasa de mortalidad específica por zona, fueron superiores para la Zona Sur respecto a la Centro-Norte. Un dato llamativo fue el aumento, en más del doble, del porcentaje de letalidad en Ia Zona Sur de Ia provincia, en el año 2016 respecto al año anterior: pasó del $17 \%$ al $37 \%$.

Existen cuatro tipos de virus de influenza: $A, B, C$ y D siendo $A$ y $B$ los de mayor importancia epidemiológica en seres humanos (6). Los subtipos AH1N1 y AH3N2, y los subtipos B linaje Victoria y Yamagata son los que circulan en la actualidad, con diferente incidencia según las regiones (1). El virus influenza A está especialmente asociado a un incremento en las consultas médicas, en las tasas de hospitalización y de mortalidad $(9,10)$. Cabe resaltar que la subtipificación viral debe entenderse con fines principalmente epidemiológicos, no clínicos, ya que el potencial epidémico de los virus influenza depende principalmente de sus variaciones antigénicas. En este sentido cobra gran importancia la vigilancia virológica Ilevada a cabo por las Unidades Centinela, al determinar no sólo el subtipo viral circulante, sino también la frecuencia, estacionalidad y distribución geográfica del virus; la concordancia entre la vacuna y las cepas en circulación; la aparición de nuevos subtipos; y al aportar cepas virales para la formulación de la vacuna de influenza (7). Resulta interesante destacar que en el año 2016 el subtipo AH3N2 se detectó en 3 casos internados, a pesar de que no hubo ningún reporte de detección de dicho tipo viral por parte de las unidades centinela (11). De esta manera, el llegar a un diagnóstico etiológico en todos los casos graves, no solo en los casos centinela, podría permitir obtener un conocimiento más completo de las características epidemiológicas de la temporada, aun cuando no sea indispensable para iniciar el tratamiento clínico. Durante el año 2016, a nivel nacional se registró una circulación intensa de influenza, predominantemente del tipo A $y$, dentro de éste, casi exclusivamente AH1N1 (10). En dicho período, en la provincia de Santa $\mathrm{Fe}$, el virus influenza $\mathrm{AH} 1 \mathrm{~N} 1$ fue el subtipo viral detectado en la gran mayoría de los casos graves internados, tanto supervivientes como fallecidos, mientras que en el año anterior lo habían sido el AH3N2, y en menor medida el virus tipo $B$.

A nivel nacional, el pico de notificación de infección respiratoria aguda grave (IRAG), se presentó entre las SE21 y SE24. Respecto a influenza específicamente (y teniendo en cuenta las categorías tanto de casos internados como casos no internados), a nivel nacional el mayor número de notificaciones se dio en la semana 22 con 1.042 casos notificados, lo que la hace la semana con mayores notificaciones luego del año pandémico 2009 (10). Habitualmente, en Argentina, el período de mayor circulación del virus de influenza se extiende desde la SE 21 hasta la 30 (2). A nivel provincial, en 2016, la gran mayoría de los casos graves se concentró dentro de dicho período, si bien el primer caso grave se detectó en la semana 17. En 2015, en el que fue más frecuentemente hallado otro subtipo viral, más de la mitad de los casos graves se detectó después de la semana 30 .

Durante el año 2016, el grupo etario que concentró la mayor cantidad de casos fue el de personas de entre 45 y 54 años (aunque la mayor tasa de incidencia se observó en menores de 1 año), mientras que en el año 2015 la mayor cantidad de casos y la mayor tasa de incidencia se registraron en el grupo de menores de 1 año. Considerando que en ambas temporadas el subtipo viral aislado con mayor frecuencia fue diferente, y que existe bibliografía en la que se describe predominancia en la detección del subtipo viral AH3N2 en los grupos etarios de menor edad $(8,9)$, sería interesante, en próximos estudios, profundizar el análisis de la relación entre la edad de las personas afectadas y el tipo viral detectado.

El número de casos graves de influenza que resultaron en muerte en 2016 representó el $20,69 \%$ del total de muertes entre casos de influenza a nivel nacional (290), siendo Santa Fe la segunda provincia con mayor cantidad de defunciones notificadas al SNVS después de Buenos Aires (10).

El número de defunciones en Santa Fe en 2016 fue casi 4,5 veces mayor que en 2015. La mayor cantidad de muertes y la mayor letalidad observadas en 2016 respecto al año anterior coincidieron con una mayor detección de virus AH1N1 (tanto entre el to- 
tal de los casos graves como entre los fallecidos), el cual presentó un mayor porcentaje de letalidad respecto a otros subtipos y tipos virales tanto en 2015 como en 2016. Kusznierz y col. (2016), en su trabajo sobre las características clínicas de los casos internados de influenza en 2013 en la provincia de Santa $\mathrm{Fe}(8)$, encontraron mayor riesgo de enfermedad severa, entendiéndose como tal a aquella que resulta en internación en cuidados intensivos o la muerte, en pacientes con detección de AH1N1 con relación a aquellos con AH3N2.

Tanto en 2016 como en 2015 , el grupo etario que presentó la mayor cantidad de muertes fue el de mayores de 65 años. A nivel nacional, en 2016, la mayor cantidad de muertes estuvo comprendida en el grupo de 45 a 64 años (10). Esto correspondería a una presentación típica de influenza estacional, en que se espera que la mayor cantidad de muertes entre los casos de influenza se produzca en los grupos etarios de mayor edad, a diferencia de una situación de pandemia. En la pandemia del año 2009, la mayor proporción de exceso de muertes relacionadas a la gripe se produjo en personas menores de 65 años (12). Por otro lado, en 2015 resultan Ilamativas las altas tasas de letalidad para la mayoría de los grupos etarios que presentaron muertes, es decir, a pesar de los pocos casos graves ocurridos por grupo ese año, un alto porcentaje terminó en muerte.

En ambos años, tanto la proporción de muertes como la letalidad fueron mayores en varones que en mujeres.

Existe evidencia de que en pacientes con cuadros graves de influenza se obtienen beneficios aun comenzando el tratamiento antiviral transcurridas 48 horas desde la aparición de los síntomas, pero que la mayor efectividad del tratamiento se consigue con la administración precoz del mismo, idealmente durante el transcurso de dicho período (13). Si bien es importante destacar que sólo se contó con información respecto a la fecha de administración del antiviral en el 36,02\% de los casos graves, se encontró asociación estadísticamente significativa entre la defunción y la administración del antiviral posterior a las 48 horas de iniciados los síntomas gripales.

\section{Factores de riesgo y vacunación}

Los factores de riesgo que se presentaron con mayor frecuencia entre los pacientes estudiados fueron la EPOC, en un $28,48 \%$ de los casos, seguida por la edad menor de 5 años y la obesidad en un mismo porcentaje $(23,84 \%)$, y por la edad de mayor de 65 años $(22,52 \%)$. Las enfermedades cardíacas y la diabetes también fueron factores de riesgo prevalentes.

A nivel nacional, el perfil de los factores de riesgo predominantes fue similar, prevaleciendo los antecedentes de enfermedad respiratoria crónica, patología cardiaca, y en menor medida, los oncológicos, la diabetes y la obesidad. Los casos fallecidos se caracterizaron en su mayoría por presentar los factores de riesgo mencionados y no estar vacunados (10).

El análisis de los factores de riesgo por separado entre los casos fallecidos y no fallecidos devolvió que la chance de morir fue significativamente mayor en casos graves de influenza que además presentaban EPOC, obesidad, diabetes, enfermedades cardíacas o edad mayor a 65, en comparación con aquellos casos graves que no tenían ninguno de dichos factores.

El $83,6 \%$ de los casos graves de influenza que fallecieron y para los que se dispuso de la respectiva información, tuvo al menos alguno de los factores de riesgo mencionados, siendo la chance de tener dichos factores significativamente mayor en este grupo respecto al grupo de pacientes que no fallecieron.

Estos resultados sugieren que los factores de riesgo analizados en estos pacientes no sólo son condiciones asociadas al desarrollo de complicaciones o formas graves de la patología sino también, y particularmente la EPOC, obesidad, diabetes, enfermedades cardíacas y la edad mayor de 65 años, constituyen condiciones asociadas a una mayor mortalidad.

Del grupo de pacientes que no tuvo ninguno de estos factores, diez fallecieron, de los cuales la mayoría era tabaquista y/o etilista, una minoría presentaba otras comorbilidades y ninguno contaba con la dosis de vacuna antigripal correspondiente.

Argentina incorporó en el año 2011 la vacuna antigripal en el Calendario Nacional de Vacunación, con el propósito de disminuir las internaciones, complicaciones, secuelas y mortalidad en la población en riesgo $(2,5)$. Del total de casos graves de influenza estudiados que contaron con antecedentes de vacuna antigripal, el $12,94 \%$ estaban vacunados, un $4,26 \%$ menos que lo registrado a nivel nacional $(17,2 \%)$ (14). A su vez, de dicho total de casos graves de la provincia, la proporción de fallecidos no vacunados fue mayor a la de fallecidos vacunados. Más del $87 \%$ de los pacientes que formaban parte de la población objetivo de vacunación, no recibió la dosis de vacuna antigripal. 
Es fundamental que todos los grupos de riesgo tengan conocimiento sobre la importancia de la inmunización en la prevención de la enfermedad y de cuadros graves; y mejorar los canales de comunicación con la comunidad y con los trabajadores de la salud para concientizar sobre el valor de las vacunas a nivel individual y comunitario, sobre la adquisición de hábitos personales saludables, y sobre la importancia de una consulta médica y tratamiento oportunos.

\section{Conclusiones}

El análisis de la información epidemiológica recabada contribuye a monitorear el trabajo del sistema de salud en lo que respecta a influenza, y organizar y priorizar los recursos de manera eficiente. Refuerza la importancia de realizar esfuerzos continuos en la prevención y promoción de la salud, el registro y notificación de los datos de los pacientes en tiempo y forma, y la vacunación oportuna, principalmente en grupos en los que la gravedad de la enfermedad puede llevar a la muerte, como en los mayores de 65 años, y pacientes con EPOC, obesidad, diabetes y enfermedades cardíacas.

\section{Agradecimientos}

M.Sc. Hugo Fernández - Departamento Programas de Salud del INER "Dr. Emilio Coni". 
Referencias

1. Daniel D. Siciliani y col. 2014. influenza: evolución a cuatro años de la pandemia Hospital Nacional Profesor Alejandro Posadas, Argentina. MEDICINA (Buenos Aires);74:189-197. ISSN 0025-7680.

2. Dirección de Epidemiología - Ministerio de Salud de la Nación. 2011. Abordaje Integral de las Infecciones Respiratorias Agudas. Guía para el equipo de salud N 6 . Segunda edición. ISSN 1852-1819 / ISSN 1852-219X.

3. Ministerio de Salud de la Nación. 2007. Manual de normas y procedimientos de Vigilancia y Control de Enfermedades de Notificación Obligatoria. Revisión nacional 2007. República Argentina.

4. Dirección provincial de promoción y prevención de la salud. Recomendaciones infecciones respiratorias agudas. 2016. Disponible en: http://www.pediatriarosario.org.ar/wp-content/uploads/2016/05/Recomendaciones-infecciones-respiratorias-agudas-2016-final.pdf.

5. Promoción y cuidados de la Salud - Gobierno de Santa Fe. 2016. Vacuna 2016 contra la gripe o influenza. Disponible en: https://www.santafe.gov.ar/index.php/web/content/view/ full/205807/(subtema)/93802)

6. National Center for Immunization and Respiratory Diseases (CDC). influenza Division. Disponible en: www.cdc.gov/flu.
7. Gabriela Kusznierz y col. 2014. Monitoreo de la actividad de influenza en Santa Fe, Argentina, 2005-2010. Rev. Chilena Infectol.;31(2):131-138.

8. Gabriela Kusznierz y col. 2016. Impact of influenza in the postpandemic phase: Clinical features in hospitalized patients with influenza A (H1N1) pdm09 and H3N2viruses, during 2013 in Santa Fe, Argentina. Research Article. Journal of Medical Virology. DOI 10.1002/jmv.24758.

9. Sandra S. Chaves y col. 2013. Patients Hospitalized With Laboratory Confirmed influenza During the 2010-2011 influenza Season: Exploring Disease Severity by Virus Type and Subtype. The Journal of Infectious Diseases. DOI:10.1093/infdis/jit316.

10. Ministerio de Salud de la Nación. Dirección Nacional de Epidemiología y Análisis de la Situación de Salud.2017. Boletín Integrado de Vigilancia. $N^{\circ} 343$. ISSN 2422-698X.

11. Instituto Nacional de Enfermedades Respiratorias "Dr. Emilio Coni". Unidad centinela de Inluenza. 2016. Boletín de Vigilancia de influenza. N 9: Sem. 47.

12. M. Susana Imaz y col. 2006. Exceso de mortalidad asociada a influenza en Argentina, 1992-2002. RevChillnfect;23(4):297-306.

13. Dirección de Epidemiología - Ministerio de Salud de la Nación. 2016. Recomendaciones sobre el uso de antivirales para influenza.

14. Ministerio de Salud de la Nación. 2017. Situación actual de la enfermedad por virus influenza y su relación con la vacuna antigripal.

\section{Characteristics of severe influenza cases in Santa Fe province during the year 2016}

\section{Summary}

Introduction: Influenza infection can lead to serious complications and put life at risk. The objective of this work was to describe the characteristics of the severe cases of influenza in Santa Fe province during the year 2016.

Materials and methods: An epidemiological description of severe cases of influenza was conducted based on data from the individual ETI (influenza-like-Diseases) files of the cases of influenza syndrome treated in the health services of the province.

Results: Of a total of 211 confirmed severe cases, 63 died. The most frequently detected viral subtype was influenza AH1N1 (87.67\%). The highest lethality occurred among those patients over 65 years old (57.58\%). The chance of dying was 2.7 times higher in cases in which the administration of the antiviral was delayed for more than 48 hours after initiation of symptoms (Cl: 1.01-7.40, $P<0.05)$. The most prevalent risk factors were COPD (28.48\%), age under 5 years and patients with obesity (23.84\%). The chance of dying was 2.4 higher in those who had at least one risk factor (OR: 2.377, 1.119-5.132, $p<0.05$ ). Of 22 vaccinated patients, 4 died (18.18\%), all had some associated risk factor. Of 148 non-vaccinated patients, 50 died (33.78\%), 40 with at least one associated risk factor.

Conclusion: The epidemiological information collected is important to organize and prioritize health resources efficiently, especially in those groups where the severity of the disease can lead to death.

Keywords: influenza, confirmed severe cases. 